\title{
Children's Inferences about Digital Tracking as a Result of Ingroup and Outgroup Differentiation
}

Sanika Kulkarni, ${ }^{*}$ Steven O. Roberts, Sarah Snay, Nicole Cuneo, and Susan A. Gelman, PhD $\dagger$

*To whom correspondence should be addressed: skulka@umich.edu

†gelman@umich.edu

Over the past few decades, a "digital revolution" has created widespread access to technology in society. While recent studies have shown that adults may express concern over the digital privacy implications of current technology use, ${ }^{1,2}$ there has been little research on children's understanding of this same issue. In the present study, 92 children (five- to 16-year-olds) and 40 adults (18- to 22-year-olds) were asked whether it was acceptable for one member of a novel group ("Hibbles" or "Glerks") to use a mobile GPS device to track an object belonging to another member of the same (ingroup) or opposite (outgroup) group. Across all ages, participants' average response to outgroup tracking was more negative $(M=-1.95, \mathrm{SE}=0.24)$ than their response to ingroup tracking $(M=-0.11, \mathrm{SE}=0.27)$, and they viewed the tracking of themselves to be more negative $(M=-1.87, \mathrm{SE}=0.25)$ than the tracking of others $(M=-0.88, \mathrm{SE}=0.24)$. However, younger children were significantly more positive about digital tracking when tracker and owner were from the same group, as compared to older children or adults. An understanding of the varying levels of moral judgment towards digital tracking at different ages has profound implications for comprehending the development of digital privacy conceptualization in children and can shape decisions made regarding children's digital security in the future.

Keywords: digital tracking, children, privacy, ingroup, outgroup

\section{References}

1. Hoofnagle, C. J.; King, J., Li, S.; Turow, J. (2010). How different are young adults from older adults when it comes to information privacy attitudes and policies?. ScholarlyCommons: University of Pennsylvania [Online] 2010. http://repository.upenn.edu/asc_papers/399

2. Norberg, P. A.; Horne, D. R.; Horne, D. A. The privacy paradox: Personal information disclosure intentions versus behaviors. Journal of Consumer Affairs. 2007 41(1), 100-126. 


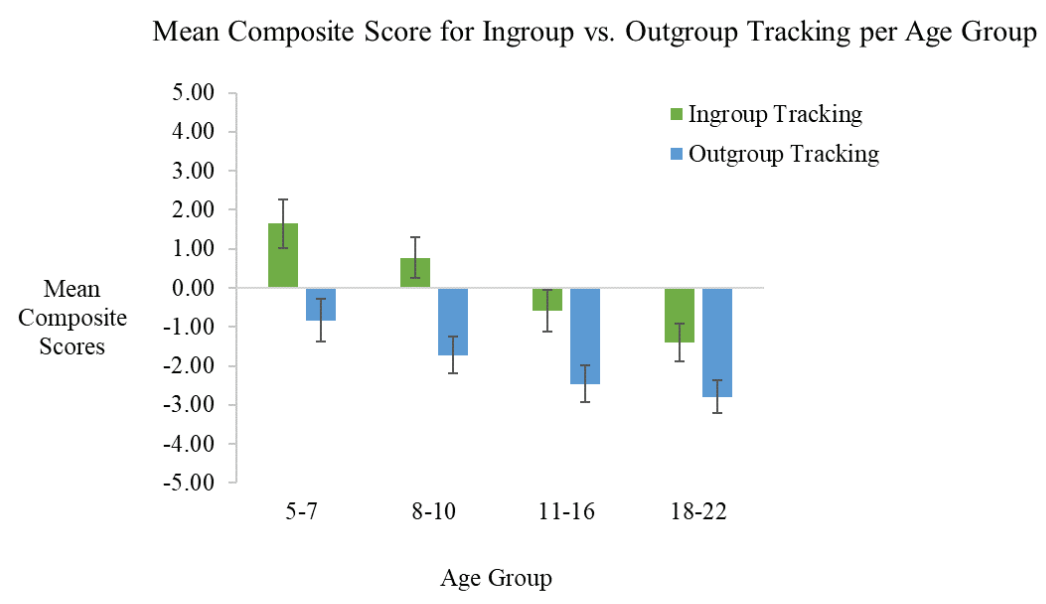

Figure 1. Mean composite ratings (and standard error) on a scale of -5 to +5 of how $\mathrm{OK} /$ not $\mathrm{OK}$ each tracking condition is as a function of age group. On average, five- to seven-year-olds and eight- to 10 -year-olds made positive assessments of ingroup tracking $(M=1.65 ; M=0.77)$ while 11 - to 16 -year-olds and 18 - to 22-year-olds made negative assessments $(M=-0.59 ; M=-1.4)$. Within each age group, participants evaluated outgroup tracking more negatively than ingroup tracking.

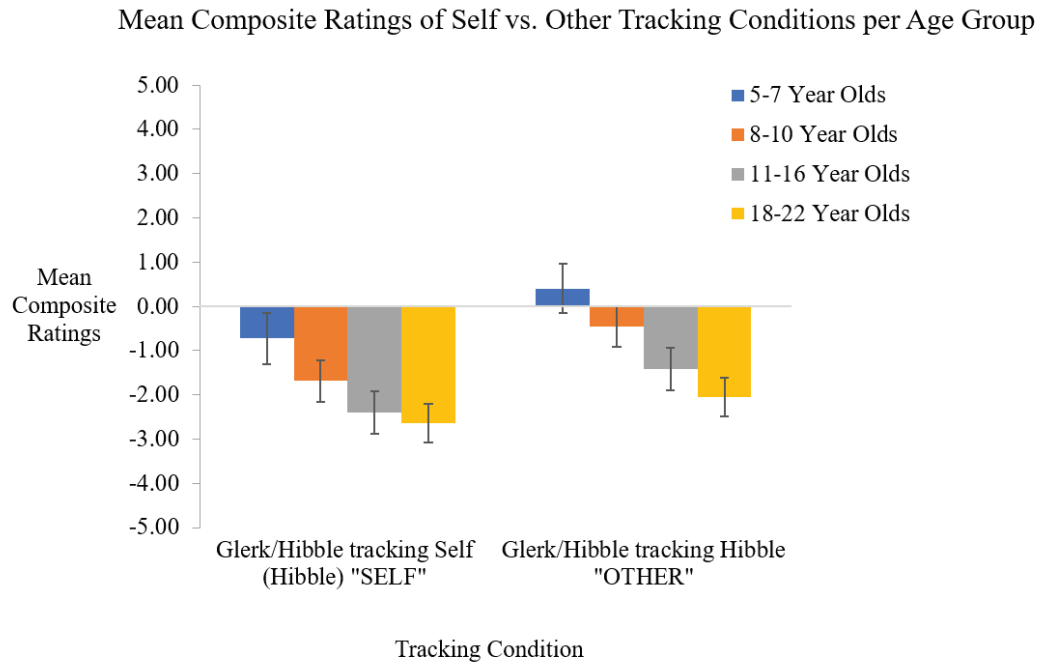

Figure 2. Mean composite ratings (and standard error) on a scale of -5 to +5 of how OK/not OK the "self" and "other" tracking conditions are as a function of age group. On average, five- to seven-year-olds made positive assessments of tracking of others $(M=0.40)$. Within each age group, participants evaluated tracking of self as more negative than tracking of others. 